\title{
COMPETÊNCIAS E HABILIDADES NO ENSINO DE ADMINISTRAÇÃO EM ENFERMAGEM À LUZ DAS DIRETRIZES CURRICULARES NACIONAIS
}

Eucléa Gomes Vale* Maria Vilaní Cavalcante Guedes**

\section{Resumo}

Este artigo apresenta uma reflexão sobre competências e habilidades no ensino de administração em enfermagem, tomando por base as Diretrizes Curriculares Nacionais, que constituem o documento norteador da educação universitária de enfermagem no Brasil. A construção de competências e habilidades para a área de administração em enfermagem faz parte de um conjunto de ações, que visam à melhoria da preparação do enfermeiro para enfrentar as transformações do mundo do trabalho. O ensino por competências deve ser direcionado para a integralidade do fazer saúde e, diante disso, apontamos algumas competências que oferecem a nossos educandos oportunidades de aprender a fazer e aprender a ser.

Descritores: diretrizes curriculares nacionais; educação em enfermagem; administração em enfermagem

\section{Abstract}

This arcticle presents a consideration about competences and skills on teaching of administration in nursing, by the guidelines of the National Curricular Guidelines, which constitute the guiding document of the nursing college education in Brazil. The construction of competences and skills for the area of administration in nursing is part of a set of actions that seek the improvement of the nurse's preparation to face the transformations of the jobs world. Teaching of competences must be directed to the integrality of the make health and, upon this, we present some competences that offer to our learners opportunities to learn to make and learn to be. Descriptors: national curricular guidelines; education on nursing; administration on nursing

Title: Competences and skills on teaching of administration in nursing by the National Curricular Guidelines

\section{Resumen}

Este artigo presenta una reflexión sobre competencias y habilidades en la enseñanza de administración en enfermería, teniendo como fundamento las Directrices Curriculares Nacionales, que constituyen el documento que nortea la educación universitaria de enfermería en Brasil. La construcción de competencia y habilidades para el área de administración en enfermería es parte de un conjunto de acciones, que visan a la mejoría de la preparación del enfermero para enfrentar las transformaciones del mundo del trabajo. La enseñanza por competencias debe ser dirigida para la totalidad del hacer salud y, por eso, apuntamos algunas competencias que ofrecen a nuestros educandos oportunidades de aprender hacer $y$ aprender a ser.

Descriptores: directrices curriculares nacionales; educación en enfermería; administración en enfermería

Título: Competencias y habilidades en la enseñanza de administración en enfermería a la luz de las Directrices Curriculares Nacionales

\section{Introdução}

A educação brasileira vem passando por uma série de reformulações, tanto em organização dos sistemas de ensino quanto em referenciais teórico-metodológicos que sugerem "novos" procedimentos para os educadores. Este momento é muito rico, por possibilitar discussões acerca do papel da educação formal e do profissional que queremos inserir no seio da sociedade. Nessa perspectiva, a implantação das Diretrizes Curriculares Nacionais - DCN permitiu que cada área revisasse o processo de formação de seus profissionais, porque além de ser uma regulamentação legal no âmbito de reforma educacional é o centro de interesse das instituições de ensino superior, das instituições de saúde (campos de prática dos futuros profissionais), dos docentes, alunos, gestores e profissionais da área que atuam nos mais variados campos de interesse social.

As discussões em torno das mudanças na educação em Enfermagem remontam a duas décadas e giram em torno da construção de propostas pedagógicas críticas, currículos integrados à realidade de cada região, articulados com os interesses da população nas comunidades, famílias, escolas, indústrias e outros espaços também reconhecidos como áreas de promoção da saúde, indo assim, além dos importantes/ indispensáveis serviços de saúde.

As discussões efetuadas em torno das mudanças curriculares concentram-se especialmente nos conteúdos a serem transmitidos, bem como nas estratégias a serem utilizadas nessa transmissão, para uma formação de qualidade.
Neste contexto, nos propomos a refletir sobre o ensino de Administração e Gerenciamento nos Cursos de Graduação em Enfermagem, à luz das Diretrizes Curriculares Nacional.

\section{Um pouco da história da educação em enfermagem no Brasil}

Os movimentos da década de 80 contribuíram significativamente na formação dos enfermeiros dentre eles podemos destacar a VIII Conferência Nacional de Saúde (1986), a promulgação da Constituição da República Federativa do Brasil (1988) e a criação do Sistema Único de Saúde (SUS), no final da década de 80, com a aprovação da Lei 8.080, de 19 de setembro de 1990

Outro fato importante da época foi a aprovação da Lei 7.498, de 25 de junho de 1986 e do Decreto 94.406, de 08 de junho de 1987, que passaram a dispor e regulamentar o exercício profissional da enfermagem brasileira.

Nessa mesma época, houve uma intensificação na criação de cursos de graduação e de pós-graduação no país. Todos esses movimentos suscitaram questionamentos e conduziram a uma nova percepção quanto à formação dos profissionais de enfermagem.

A Associação Brasileira de Enfermagem - ABEn, consciente do seu papel nas discussões e elaboração das propostas que dizem respeito à educação em Enfermagem, realizou vários seminários e oficinas estaduais, regionais e nacionais, em parceria com representantes da Comissão de Especialistas em Ensino de Enfermagem (Secretaria de Ensino Superior -MEC), de escolas do país e com outras entidades de

\footnotetext{
* Enfermeira. Mestre em Educação. Presidenta de la Federación Panamericana de Profesionales de Enfermeria e Coordenadora do Curso de Graduação em Enfermagem da Faculdade Católica Rainha do Sertão-Quixadá-CE. **Enfermeira. Livre Docente da Universidade Estadual do Ceará e Doutoranda do Programa de Pós-Graduação em Enfermagem da Universidade Federal do Ceará

E-mail do autor: euclea@terra.com.br
} 
classe, em um processo de discussão, reflexão e ação com vistas à formulação dos currículos que culminou com uma proposta curricular consensuada de forma participativa que, após avaliação do Ministério da Educação - MEC, foi aprovada pela Portaria 1721, de 15 de dezembro de 1994. No entanto, esta Portaria sofreu alterações que excluíram as disciplinas educativas e as de assistência ao idoso.

Esta Portaria propunha um currículo de graduação em Enfermagem com seis áreas assim distribuídas: 1 fundamentação básica de enfermagem; 2 - métodos e técnicas na enfermagem; 3 - enfermagem na assistência à formação e nascimento do ser humano; 4 - enfermagem na assistência à saúde da criança e do adolescente; 5 - enfermagem na assistência ao idoso; 6 - enfermagem e administração.

Após a aprovação da Portaria 1721/94 do MEC, foram efetuadas algumas modificações que culminaram com a apresentação das seguintes áreas temáticas:

Bases Biológicas e Sociais da Enfermagem: nesta área, compreendendo $25 \%$ de carga horária do curso, incluem-se conteúdos fundamentais das Ciências Biológicas e das Ciências Humanas.

Fundamentos de Enfermagem: nesta área, compreendendo $25 \%$ da carga horária do curso, incluem-se obrigatoriamente os conteúdos técnicos, metodológicos e os meios e instrumentos inerentes ao trabalho do enfermeiro e da Enfermagem, na assistência de Enfermagem em nível individual e coletivo (em hospitais, ambulatórios e rede básica de serviços de saúde).

Assistência de Enfermagem: nesta área, compreendendo $35 \%$ da carga horária do curso, incluem-se obrigatoriamente os conteúdos (teóricos e práticos) que compõem a assistência de Enfermagem em nível individual e coletivo prestada à criança, ao adolescente e ao adulto.

Administração em Enfermagem: nesta área, compreendendo $15 \%$ da carga horária do curso, incluem-se obrigatoriamente os conteúdos (teóricos e práticos) de administração do processo de trabalho de Enfermagem e da assistência de Enfermagem, priorizando hospitais gerais e especializados de médio porte, ambulatórios e rede básica de serviços de saúde.

Além do conteúdo teórico e prático desenvolvido ao longo da formação do enfermeiro, ficam os cursos de enfermagem obrigados a incluir no currículo o estágio supervisionado em hospitais, ambulatórios e rede básica de serviços de saúde ${ }^{(1)}$.

Esta proposta com carga horária total de 3.500 horas e o estágio curricular supervisionado de dois semestres, com duração do curso de no mínimo quatro anos (oito semestres letivos) e no máximo seis anos (doze semestres letivos), não atendeu aos anseios da categoria por excluir disciplinas educativas e por estabelecer percentuais das áreas que compõem o novo currículo. Este estabelecimento de percentuais configurando a lógica do controle sobre conteúdos e formas, limita a formação do perfil profissional generalista, sem considerar as vocações das escolas, nem as características institucionais e geopolíticas nas quais estão localizadas ${ }^{(2)}$.

A regulamentação da Lei 9.394 , de 20 de dezembro de 1996, Lei de Diretrizes e Bases da Educação - LDB, em seu artigo 53, deu plenos poderes ao MEC de fixar os currículos dos seus cursos e programas por meio das comissões de Especialistas do Ensino de Graduação, que estabeleceram as DCN. Assim, a Comissão de Especialistas de Ensino de Enfermagem - CEEnf, da SESu, do Departamento de Políticas de Ensino Superior (DEPES), no Ministério da Educação, elaborou um modelo de enquadramento das Propostas de Diretrizes Curriculares, que não contemplou as discussões realizadas nas entidades de classe e nas organizações de ensino, amplamente defendidas pela $\mathrm{ABEn}^{(3)}$.

Quando em 2000, assumiu uma nova CEEnf - SESu MEC, novas discussões foram efetuadas pela ABEn nos
Seminários Nacionais de Diretrizes para a Educação em Enfermagem (SENADEn), nos Fóruns de Escolas de Graduação em Enfermagem e com base na Carta de Florianópolis, aprovada no $51^{\circ}$ Congresso Brasileiro de Enfermagem e $10^{\circ}$ Congreso Panamericano de Enfermería, realizados em outubro de 1999 em Florianópolis - SC, culminando com a elaboração de uma proposta que contemplou as seguintes dimensões: o perfil do profissional numa perspectiva generalista, crítica e reflexiva. Competências e habilidades geral e específicas; tópicos de estudos com base na Portaria 1.721/94, duração do curso com carga horária mínima de 3.500 horas, sendo 500 horas de estágio supervisionado, no final do curso; atividades complementares; reconhecimento de habilidades, monografia e a estrutura geral do curso articulando ensino, pesquisa e extensão.

O conteúdo desta proposta foi contemplado, em sua maioria, pelo Conselho Nacional de Educação - CNE/MEC, no documento final das DCN, tendo ficado em aberto a definição da carga horária, que será fixada pela Instituição de Ensino Superior - IES. No entanto, os enfermeiros comprometidos com a formação de novos profissionais defendem uma carga horária mínima de 3.500 horas, como foi aprovada na Carta de Florianópolis.

Resgatamos aqui avaliações e críticas efetuadas nos últimos anos sobre os pressupostos que norteiam o ensino de Enfermagem, ou seja, a ênfase exagerada na tecnologia e no modelo hospitalocêntrico, que não têm atendido às necessidades de saúde dos usuários.

Lembramos, porém que nenhum projeto, diretriz ou idéia, mesmo que bem fundamentado, discutido e consensuado, garante a viabilização de se formar um profissional completo. Na realidade, os projetos são importantes para orientar nossos caminhos e para expressar posições e desejos de mudanças que com certeza, contribuem para concentração de esforços coletivos, no entanto, não viabilizam as condições para o fazer/transformar.

\section{Competências e suas repercussões no trabalho e na educação de enfermagem}

Quando se ouve a palavra competência, rapidamente relacionamos com saber, conhecimento, experiência e a ação de fazer com qualidade. Nessa perspectiva, o termo foi inicialmente incorporado pelo mundo do trabalho e, em seguida utilizado nas propostas de formação e atualização profissionais. Assim, esse termo passa a ser relacionado com articulações entre saberes e fazeres no âmbito educativo e de qualificação na esfera do trabalho ${ }^{(4)}$.

O termo competência vem sendo usado com uma freqüência cada vez maior nos campos educacional e do trabalho. As diretrizes preconizadas para a educação neste século XXI, apontam para a necessidade de que todos os profissionais de saúde sejam dotados de competências (conhecimentos e atitudes), possibilitando a sua participação e atuação multiprofissional, beneficiando os indivíduos e a comunidade ${ }^{(5)}$.

A palavra competência também tem sido trabalhada para designar qualificação, embora tenham significados diferentes. A noção de qualificação está intrinsecamente ligada ao repertório teórico das ciências sociais, enquanto que competência está ancorada nas ciências humanas e atrelada a capacidade e habilidades ${ }^{(6)}$.

Na esfera do trabalho a competência está embasada em três propósitos ${ }^{(7)}$ :

a compreensão da relação existente entre trabalho e educação, deslocando o foco dos empregos, das ocupações e das tarefas para o trabalhador em suas implicações com o trabalho;

a institucionalização de novas formas de educar/formar os trabalhadores e de gerir o trabalho internamente às organizações e no mercado de trabalho em geral, com novos códigos profissionais em que estão explícitas as relações contratuais, de carreira e de salários; 
a formulação de padrões de identificação da real capacidade do trabalhador para uma ocupação específica, de tal maneira que possibilite mobilidade entre as diversas estruturas de emprego em todos os níveis.

Acrescentamos que neste âmbito, ao termo competência são adicionadas noções de autoridade, capacitação e qualificação. Desta maneira

competência refere-se a funções, tarefas e atuação de um profissional-incumbência para desenvolver, adequada e idoneamente, suas funções de trabalhosuficiência, que é resultado e objeto de um processo de capacitação e qualificação(8:3).

Neste contexto, cada atividade educacional deve apoiar o educando no desenvolvimento das competências, destinadas a melhorar os aspectos da sua personalidade, levando-o a uma melhor qualidade de vida, com harmonia pessoal e em equipe. Para que ocorra a ampliação das habilidades pessoais e interpessoais, deve ser considerado o aumento de uma imagem positiva de si mesmo, a capacidade de trabalhar individualmente e em equipe, a liderança, a autoconfiança, a negociação e resolução de $\operatorname{conflitos}^{(5)}$.

No entanto, o que percebemos na formação para o trabalho é o preparo, quase que exclusivo, para desempenhar funções/tarefas específicas e operacionais. Esta modalidade de formação está fundamentada em uma concepção comportamental rígida, que preconiza que o processo ensinoaprendizagem das tarefas/habilidades devem ocorrer em uma seqüência lógica, objetiva e operacional, enfatizando os aspectos técnico-operacionais em detrimento de sua fundamentação mais teórica e ampla(6).

$\mathrm{Na}$ esfera da educação, competência se traduz na capacidade de mobilizar recursos cognitivos que agregam saberes, informações, habilidades operatórias e, essencialmente, as inteligências, para com eficácia e pertinência, enfrentar e solucionar uma série de situações ou problemas. Competência está relacionada a forma de organizar e direcionar situações de aprendizagem, administrar a evolução das aprendizagens; criar e fazer evoluir os dispositivos de diferenciação, envolver os alunos em seu processo de aprendizagem, bem como em seu trabalho; discutir o enfrentamento dos deveres e dilemas éticas da profissão e administrar sua formação contínua ${ }^{(9)}$.

Na Enfermagem, o termo competência refere-se a capacidade de conhecer e agir sobre determinadas situações, envolve habilidades para desenvolver ações/atividades (planejamento, implementação e avaliação), requerendo experiência para o fazer com qualidade.

Neste contexto, ressaltamos os pilares da educação expressos nas DCN que se propõem a favorecer aos educandos a aprender a aprender que engloba aprender a ser, aprender a fazer, aprender a viver juntos e aprender a conhecer, na perspectiva de contribuir para capacitação de profissionais com autonomia e discernimento para possibilitar a integralidade da atenção e a qualidade e humanização do atendimento prestado aos indivíduos, famílias e comunidades ${ }^{(10)}$.

\section{Diretrizes Curriculares Nacionais e as competências para o ensino das disciplinas administração e gerenciamento em enfermagem}

As DCN dos cursos de Graduação em Enfermagem definem: perfil do formando, competências gerais e específicas, habilidades, conteúdos curriculares, estágios, atividades complementares, organização do ensino, acompanhamento e avaliação.

As competências gerais envolvem aspectos relacionados ao preparo do profissional para: atenção à saúde, tomada de decisões; comunicação; liderança; gerenciamento e educação permanente.
Neste estudo, com base no documento das DCN, abordaremos com maior ênfase as competências e habilidades que têm relação direta com o ensino da Administração e Gerenciamento em Enfermagem. Assim, chamamos a atenção para a Tomada de Decisões que diz respeito à capacitação do futuro profissional para avaliar, sistematizar e decidir as condutas mais adequadas, baseadas em evidências científicas. Comunicação para interagir com outros profissionais e com o público em geral. Liderança no trabalho em equipe multiprofissional, envolvendo compromisso, responsabilidade, empatia, habilidade para tomada de decisões, comunicação e gerenciamento de modo efetivo e eficaz. Administração e gerenciamento da força de trabalho, dos recursos físicos e materiais e de informação, além de estar apto para desenvolver o empreendorismo, a gestão, para ser empregador ou líder na equipe de saúde ${ }^{(10)}$.

Com esse entendimento às competências e habilidades específicas para a área de administração em enfermagem, desenvolvidas durante o processo de formação, devem privilegiar as condutas técnico-científicas, ético-políticas, sócioeducativas de forma a permitir ao futuro profissional, reconhecer a saúde como direito, atuando para garantir a qualidade da assistência em todos os níveis de atenção à saúde, planejando, organizando, gerenciando e avaliando o processo de trabalho em enfermagem-saúde, em parceria com outros profissionais da mesma instituição.

Os conteúdos curriculares sugeridos pelas DCN apontam para a necessidade de se dar ênfase à administração do processo de trabalho e da assistência de enfermagem por meio de atividades teóricas e práticas.

Assim, apresentamos nesta reflexão competências específicas para preparar enfermeiros para o exercício da administração / gestão em enfermagem /saúde.

1. Planejamento e organização de serviços de enfermagem/ saúde

2. Gerência de serviços de enfermagem/saúde

3. Gestão do trabalho em enfermagem/saúde

4. Planejamento e gestão financeira

5. Gestão de recursos físicos e materiais

6. Gestão da informação em enfermagem/saúde

7. Desenvolvimento de políticas e planificação de propostas de atenção à enfermagem/saúde

8. Gestão do processo de cuidar em enfermagem

9. Elaboração de estratégias de avaliação, controle, auditoria e acreditação de serviços de saúde/enfermagem

10.Coordenação da educação em serviço

\section{Dizendo ainda que...}

As competências definidas nas DCN, apesar de atender a grande parte dos interesses da categoria, têm suscitado críticas e rejeições na sua compreensão e implementação, fato justificado pela concepção tecnicista que subjaz a esta, bem como pela idéia de qualificação, que muitas vezes, está atrelada a produção no modelo de organização capitalista do trabalho.

Não podemos esquecer que as competências da forma como estão explicitadas nas DNC, em alguns pontos, trazem conotações subjetivas que dão margem a múltiplas interpretações.

Acreditamos serem oportunas as seguintes questões para reflexão: 1- Como transpor o atual modelo de ensino para o modelo baseado em competências? 2- Até que ponto estão sendo trabalhadas as competências gerais e específicas na área de administração e gerenciamento em enfermagem? 3Apesar do caráter inovador, não está este modelo subsidiado pela lógica do capital em detrimento da lógica do trabalho? 


\section{Referências}

1. Ministério da Saúde (BR). Assessoria de Comunicação Social. Lei orgânica da saúde. $2^{a}$ ed. Brasília: Assessoria de Comunicação Social; 1991. 7-31.

2. Ministério da Educação (BR). Portaria $n^{\circ} 1.721$, de 15 de dezembro de 1994. Dispõe sobre o novo Currículo Mínimo de Graduação em Enfermagem. Brasília (DF): Diário Oficial [da] República Federativa do Brasil, Brasília (DF) 1994 dez 16; 238 seção 1: 19801-2.

3. Backes VMS. Estilo de pensamento e práxis na enfermagem: a contribuição do estágio pré-profissional [tese de doutorado em Enfermagem]. Florianópolis (SC): Universidade Federal de Santa Catarina; 1999, $281 \mathrm{f}$

4. Vale EG, Guedes MVC. A nova política de educação e suas implicações nos cursos de graduação de enfermagem: apreciação crítica da Associação Brasileira de Enfermagem - ABEN. In: CBEn. Anais do $51^{\circ}$ Congresso Brasileiro de Enfermagem; $10^{\circ}$ Congreso Panamericano de Enfermería: Enfermagem: situando-se no mundo e construindo o futuro, 1999 out 2-7; Florianópolis (SC), Brasil. Florianópolis (SC): ABEn; 2000: 370-8.

5. Carta de Florianópolis. In: CBEn. Anais do $51^{\circ}$ Congresso Brasileiro de Enfermagem; $10^{\circ}$ Congreso Panamericano de Enfermería: Enfermagem: situando-se no mundo e construindo o futuro, 1999 out 2-7; Florianópolis (SC), Brasil. Florianópolis (SC): ABEn; 2000.41320.
6. Desaulniers JBR. Formação, competência e cidadania. Educação \& Sociedade, Campinas (SP) 1997 dez; 18 (60): 51-63.

7. Organización Panamaricana de la Salud. Organización Mundial de la Salud. División de desarrollo de sistems y servicios de salud (HSP). Programa de desarrollo de recursos humanos (HSR). El desafio educativo de lãs reformas sectoriales: câmbios em la capacitación y la capacitación em salud. Grupo de trabajo sobre evaluación de la capacitación em salud. Buenos Aires;1997. 33f.

8. Manfredi SM. Trabalho, qualificação e competência profissional das dimensões conceituais e políticas. Educação \& Sociedade 1998 Set; 19 (64);13-49. Ramos MN. A pedagogia das competências: autonomia ou adaptação? São Paulo (SP): Cortez; 2001, 320 p.

9. Tejada JF. Acerca de lãs competências profesionales. Herramientas, Madrid 2001 ago. [56 p.]. Disponível em: URL: http://www.ilo.org/ public. Acessado em: 16 ago 2001.

10.

11. Perrenoud P. 10 novas competências para ensinar. Porto Alegre(RS): Artmed;2000.192p.

12. Conselho Nacional de Educação (BR). Parecer do CNE/CES n. 1133 de 7 de agosto de 2001. Brasília (DF); 2001: $37 f$.

Data de Recebimento: 30/07/2004

Data de Aprovação: 27/09/2004 